\section{Inclusión \\ digital \\ democratización \\ conocimiento. Los Proyectos \\ Flor de Ceibo y Flor de Ceibo \\ Conecta2 en diálogo con las \\ políticas públicas}

UTE. Revista de Ciències de l'Educació

2019 núm. 1. Pag. 48-60

ISSN 1135-1438. EISSN 2385-4731

http://revistes.publicacionsurv.cat/index.php/ute

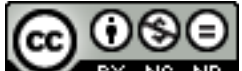

https://doi.org/10.17345/ute.2019.1

\author{
María Julia Morales-González \\ Rebut: 21/06/2019 Acceptat: 10/07/2019
}

\begin{abstract}
Resumen
La inclusión digital fue vista a principios de la década del 2000 como un paso imprescindible para la inclusión social en un mundo altamente tecnologizado, que permea todos los ámbitos donde las personas interactúan. Para lograr la inclusión digital de sus ciudadanos, los distintos países implementaron distintas políticas, cuyas estrategias estarán signadas por la orientación política e ideológica (Lago et al, 2015).Uruguay no fue ajeno a este fenómeno y en el ámbito educativo surgió el Plan Ceibal. Esta política vista como revolucionaria dentro y fuera de fronteras, vehiculizó su implementación a través de la escuela pública, importante referente de identidad nacional (en Uruguay) que fuera construida bajo los valores de la educación, la cultura y la homogeneidad de su población. En este contexto la Universidad no podía quedar ajena y desarrolla los Proyectos Flor de Ceibo (2008-2017) y Flor de Ceibo Conecta2 (2017-actualidad), acompañando crítica y reflexivamente el Plan Ceibal, a través de la integralidad, donde se conjuga enseñanza, investigación y extensión, con una metodología de abordaje por problemas, buscando facilitar la apropiación tecnológica, el desarrollo de competencias y la democratización del conocimiento, en un escenario de 2da Reforma Universitaria.
\end{abstract}

Palabras claves: Inclusión digital, democratización del conocimiento, Integralidad, abordaje por problemas, educación superior

\begin{abstract}
Digital inclusion was seen at the beginning of the 2000s as an essential step for social inclusion in a highly technological world, which permeates all areas where people interact. To achieve the digital inclusion of its citizens, the different countries implemented different policies, whose strategies will be marked by political and ideological orientation (Lago et al, 2015). Uruguay was not oblivious to this phenomenon and in the educational field, the Plan Ceibal arrived. This policy, seen as revolutionary both inside and outside borders, conveyed its implementation through the public school, an important reference point for national identity (in Uruguay) and a carrier, which was built under the values of education, culture and the homogeneity of its population. In this context, the University could not remain oblivious and develops the Flor de Ceibo and Flor de Ceibo Conecta2 Projects, critically and reflexively accompanying the Plan Ceibal, through integrality, where education, research and extension are combined, with a methodology of approach for problems, seeking to facilitate technological
\end{abstract}


UTE. Revista de Ciències de l'Educació

2019 núm. 1. Pàg. 48-60
Inclusión digital y democratización del conocimiento. Los Proyectos Flor de Ceibo y Flor de Ceibo Conecta2 en diálogo con las políticas públicas

appropriation, the development of skills and the democratization of knowledge, in a scenario of Second University Reform.

Key words: Digital inclusion, Knowledge democratization, Integrality, Problem solving Higher Education.

\section{La inclusión digital y su relación con la inclusión social}

La inclusión digital definida como un "conjunto de políticas públicas relacionadas con la construcción, administración, expansión, ofrecimiento de contenidos y desarrollo de capacidades locales en las redes digitales públicas, en cada país y en la región" surge con el desarrollo de la primera fase de la Cumbre Mundial de la Sociedad de la Información en 2003 (Lago, Amado, Álvarez, Andonegui y Soto, 2016).

Para Lago et al. este significado atribuido a la inclusión digital lo otorgan los gobiernos y organismos internacionales, orientadores de las políticas públicas y fue promovido por la Unión Europea en la década de 1990, ampliando la noción de pobreza y por tanto el espectro de "carencias en relación a la inserción social y laboral y la materialización de derechos sociales y relaciones sociales", incorporándose la exclusión al acceso y manejo de las tecnologías digitales, entendiéndola como parte de la exclusión social. Asimismo, sostienen que la inclusión digital y la inclusión social, son "conceptos ambiguos y relacionales (respecto de la exclusión) que cuentan con al menos tres dimensiones: una discursiva e ideológica, otra institucional o política (procesos de decisión) y finalmente la operativa." (2016, pp. 6-7) "De manera que depende de la orientación política e ideológica de que se trate se priorizarán diferentes estrategias para las políticas públicas" (Lago, Amado y Vidaurre, 2015).

En el mismo sentido, Cabello (2014) menciona que los distintos países se posicionan y toman iniciativas para la inclusión de la ciudadanía en la Sociedad de la Información, entendiendo a la inclusión digital, aún con reservas conceptuales, como el proceso que posibilita la disminución de las desigualdades respecto a la integración de las personas y por tanto de las sociedades en un mundo inmerso en la información a través de las tecnologías digitales interactivas, estableciendo en muchos de los casos una "vinculación directa entre inclusión digital e inclusión social" (2014 p. 4).

Profundizando, Lázaro (2015) sostiene que las tecnologías digitales son un elemento clave a la hora de pensar la transformación digital y de la ciudadanía digital. Asociado a esto se encuentran las recomendaciones de UNESCO $(2005,2009)$ de garantizar el acceso universal a las tecnologías digitales para resguardar los principios de educación inclusiva y con equidad.

Para lograr estos objetivos y asegurar la inclusión digital los principales factores son: "1. La gestión estratégica en su sentido más amplio: político, económico, cultural, pedagógico...; 2. La generalización del acceso a la tecnología, tanto en términos de accesibilidad como en compensación de los diferentes niveles de desarrollo social y 3. La formación de los docentes en términos de CDD" (Lázaro, 2015, p 43).

En suma, la inclusión digital fue vista a principios de la década del 2000 como un paso imprescindible para la inclusión social en un mundo altamente tecnologizado y que permea en todos los ámbitos donde las personas interactúan. Atendiendo a este nuevo fenómeno, los diferentes países incluyeron agendas digitales para el desarrollo de la Sociedad de la Información y el Conocimiento (SIC) y para la inclusión digital de su ciudadanía; Uruguay no fue ajeno a esto, ha desarrollado a través de los años agendas digitales en este sentido. 
En la "Agenda Digital 2020: transformación con equidad", en su Meta 1: Políticas sociales e inclusión: Las tecnologías digitales en la transformación de la estructura de oportunidades", la Agencia para la Gestión del Gobierno electrónico y la Sociedad de la Información y el Conocimiento de Uruguay (AGESIC) sostiene que a pesar de todo lo avanzado y reconociendo que las tecnologías digitales contienen un potencial de transformar la estructura de oportunidad en Uruguay, es necesario "focalizarse en la disminución de las brechas digitales generadas por la adquisición desigual de competencias, motivando el interés y la formación de habilidades cada vez más sofisticadas" (AGESIC, 2016 p.9).

\section{Apropiación social de las tecnologías digitales}

Una breve aproximación a los conceptos de apropiación social de las tecnologías nos permitirá entender más adelante los objetivos de los proyectos a que hacemos referencia en este artículo.

Para Martínez y Gómez la real apropiación o el uso con sentido implica que "la gente absorbe, sistematiza y transforma la información y las nuevas relaciones en nuevos conocimientos, que pueden ser trasmitidos a otros(as) y aplicados para resolver sus necesidades concretas" (2001 p.2), mientras que para Kemly Camacho - aunque refiriéndose a Internet, bien puede pensarse en otras herramientas tecnológicas - implica la existencia de estrategias de uso y uso estratégico donde primero deben identificarse las necesidades o problemas propios, entender qué tecnologías pueden ayudarnos a solucionarlos, para luego hacerlo efectivo, construyendo conocimiento nuevo al respecto (Camacho, 2001).

Todo esto implica una reflexión crítica acerca de las tecnologías y su relación con la realidad vivida, en la cual según la clasificación de Castells (1997), seremos "interactuantes" y no "interactuados", "(...) aquellos capaces de seleccionar sus circuitos de comunicación multidireccionales y aquellos a los que se les proporciona un número limitado de opciones pre-empaquetadas" (p.404). El concepto de apropiación tecnológica o la consecución de la misma estarán signados por diferencias educativas/culturales pre-existentes a la tecnología (Castells, 1997).

Por último Da Silva y López (2014) sostienen que para que exista apropiación social de la tecnología deben gestarse distintas transformaciones. Un primer movimiento involucra a las personas en función del uso de las tecnologías. Un segundo movimiento de transformación colectiva, que acompañe dichos procesos y dé sentido, vinculado a la transformación de nuevas prácticas de uso de la tecnología y de generación de conocimiento.

Al respecto García-Urea dirá "(...) al hablar de apropiación de la tecnología, (que) no podemos pensar en un solo actor (el usuario), sino que necesariamente debemos introducir en la ecuación las interacciones del usuario con otros actores y con la tecnología, la flexibilidad interpretativa de la tecnología (significados que adquiere), las representaciones sociales que hace el usuario y que derivan de sus necesidades y de su propia realidad y las que hace quien inventa la tecnología sobre los usos reales y potenciales de la tecnología." (García-Urea, 2007, p.4).

\section{Políticas para la inclusión digital en Uruguay: ¿Por qué el Plan Ceibal a través de la escuela pública uruguaya?}

Si bien Uruguay ha desarrollado políticas de inclusión en la Sociedad de la Información desde hace décadas, en el actual contexto internacional y luego de la Cumbre Mundial de la Sociedad de la 
Información, estas se han profundizado y se han realizado acciones sistemáticas a partir de la asunción de gobiernos de izquierda (Morales, 2017; Rivoir, 2013).

Entre las políticas públicas de alcance universal, se ha implementado en 2007 el Plan Ceibal por medio de la cual se otorga una computadora portátil - generalmente denominada ceibalita - a todos los niños y niñas de la enseñanza pública de nuestro país. Comienza con un piloto en 2007 en la ciudad de Cardal en Florida, para ampliarse al interior del país en 2008 y llega a Montevideo en 2009. A partir de 2010 se extiende a los estudiantes de enseñanza secundaria y estudiantes y docentes de formación inicial docente; también alcanza mediante convenios a algunas instituciones de enseñanza primaria privada del país (Da Silva y Morales 2010; Morales, 2017; Rivoir y Lamschtein 2012; Uriarte y Morales, 2014).

El Plan Ceibal se compone de 3 áreas principales: a) una educativa, que involucra la mejora de la calidad de la educación, mediante la incorporación de las TIC; b) una social, que intenta acciones en busca de equidad, permitiendo el acceso universal a computadores e Internet y c) una tecnológica que facilita los anteriores y refiere a la infraestructura y la conectividad. Atendiendo estas tres áreas persigue la inclusión digital de la ciudadanía uruguaya, accediendo a través de una educación inclusiva, universal y pública (Da Silva y Morales 2010; Uriarte y Morales, 2014).

Los agentes de gobierno que impulsaron el Plan Ceibal e incluso la ciudadanía entendieron el plan como muy ambicioso al mismo tiempo que revolucionario; trascendiendo lo meramente educativo era percibido como una acción concreta enmarcada en una corriente de cambios en el país, evaluándola como una política de desarrollo social principalmente (Uriarte y Morales, 2014).

Tabaré Vázquez, presidente de Uruguay entre 2005-2009 fue quien implementó el Plan CEIBAL y lo definía como "...una revolución en tanto proceso de cambios profundos e irreversibles que abren paso [...] a un mundo mejor en la medida que ofrece a todos más posibilidades de igualdad ante la ley, pero sobre todo la posibilidad de igualdad a todos ante la vida, que es lo más importante" (Grandi, 2009, p. 12).

No debería extrañar la elección de la escuela pública como vehículo para la implementación del Plan Ceibal, esta es un importante referente de la identidad nacional, que fue construida bajo los valores de la educación, la cultura y la homogeneidad de su población; bajo esta realidad y sumido el país (en la década del 2000) en una importante crisis, que agudizaron y profundizaron una situación de dificultades socio-económicas estructurales de por lo menos tres décadas (dictadura militar y primeros años de reconstrucción democrática); "la propuesta de reconstruir los principios de igualdad y educación, a partir del acceso universal a una computadora portátil, significaba - en cierta medida - la reconstrucción del país" (Uriarte y Morales, 2014).

"Como política pública integrada, el Plan CEIBAL encuentra su sentido en el propósito explícito de la construcción progresiva de una sociedad igualitaria y más justa, poniéndose énfasis en la inclusión social. Pero la viabilidad de este plan está centrada y garantizada por la educación, ya que esta es la vía mediante la cual se forma a las personas $y$, en este caso, se promueve el desarrollo de competencias digitales regidas por criterios humanistas" (Moraes, 2009, p. 16).

Visto esto como un gran desafío, en medio de un sistema escolar público cuyas estructuras estaban debilitadas, significó "de algún modo, otorgar nuevamente el lugar a la escuela pública como un espacio institucional en el cual alojar un proyecto colectivo" (Uriarte y Morales, 2014).

Para entender mejor esta situación, se necesita dar una perspectiva histórica y debemos de incluir el surgimiento de la escuela pública para pensar en una narrativa nacional. 
La escuela pública, parte importante en la construcción de una identidad nacional, caracterizada por la homogeneidad cultural, étnica y religiosa (D’Ambrosio, 2009), se reconoce como un proyecto de homogeneización que "entendía la estabilidad política como la eliminación de lo que pudiera alterar la norma" (Uriarte y Morales, 2014, p.3); junto a este proyecto coexistió la idea de la escuela como un proyecto político para la formación de ciudadanos.

Así lo expresan los investigadores Bordoli y Romano:

"... la Escuela como proyecto se configuró como la institución que hacía posible la concreción de la República por medio de un mandato específico: la inscripción de los sujetos en la cultura. En otros términos, el proyecto escolar como proyecto político-pedagógico, presuponía la constitución de un sujeto pensante $y$, por ende, autónomo, e inscripto en la cultura como condición de la formación de ese cuerpo político que sería capaz de darse sus propias leyes" (Bordoli y Romano, 2009, p.17).

Estas dos visiones y discursos acerca del alcance como proyecto de la escuela pública uruguaya (homogeneidad y construcción de sujetos críticos) serán retomadas desde la Universidad de la República al pensar los objetivos del Plan Ceibal; generando un diálogo entre la Universidad y los actores involucrados en la implementación del Plan, pensando en la "posibilidad de convertirse en una política pública de gran alcance como en la necesidad de pensar las vinculaciones entre tecnología y educación, para poner la tecnología al servicio de un proyecto pedagógico, y no lo contrario" (Uriarte y Morales, 2014 p.3).

$Y$ " [...] se sitúa en el marco de su objetivo de construir sociedades del conocimiento, que se basan sobre cuatro pilares fundamentales: la libertad de expresión, el acceso universal a la información y al conocimiento, el respeto a la diversidad cultural y lingüística, y la educación de calidad para todos. Promoviendo el acceso universal a la información y al conocimientos, y mejorando la calidad de la educación, el uso de las TIC en la educación constituye una herramienta fundamental de la sociedad del conocimiento" (Grandi, 2009, p.13).

Una de las características que se vieron como fortalezas del Plan, fue que la computadora fuera otorgada en propiedad a los niños/as de las escuelas públicas, de este modo se trascendía el espacio escolar formal, llegando a los hogares y por tanto a todos sus miembros. Otras políticas orientadas al reforzamiento de la educación primaria, que interactuaron con el Plan Ceibal fue el Programa de Maestros Comunitarios, esto es resultado novedoso de tener presente en el diseño de las políticas educativas el ámbito del hogar de donde provienen estos niños y niñas (Almirón, Folgar y Romano, 2009).

"Desde el comienzo de CEIBAL se produjo esta conjunción al punto de que, en muchas escuelas, un actor clave en su implementación lo constituyó el maestro comunitario. Los encuentros de ambas estrategias han ocurrido tanto en el ámbito escolar como en el seno de los hogares. [...] el Programa de Maestros Comunitarios y el Plan CEIBAL comparten el reconocimiento de la necesidad de articular nuevos modos en la relación de la escuela con la familia, trayendo consecuencias para la escuela [...] impactan directamente sobre la vida de los hogares; pero también se produce un efecto de rebote en la institución, que habilita la posibilidad de que la escuela pueda replantearse los límites de sus fronteras." (Almirón et al, 2009, pp.46-47).

Sumado a los desafíos que impuso el Plan al sistema educativo, en particular significó la interpelación a los docentes, quienes en su gran mayoría cuestionario fuertemente el Plan, era visto como el agente de todos sus males, cuestionando sus capacidades, interpelando sus prácticas y en un primer momento 
UTE. Revista de Ciències de l'Educació

2019 núm. 1. Pàg. 48-60
Inclusión digital y democratización del conocimiento. Los Proyectos Flor de Ceibo y Flor de Ceibo Conecta2 en diálogo con las políticas públicas

dispuesto externamente al sistema educativo, sin consulta y sin capacitación; vale recordar que este Plan fue implementado bajo decreto presidencial.

Sin embargo, las familias y la sociedad en su conjunto era consciente de la inversión económica que estaba realizando el país y por tanto la implementación del Plan sentía la presión de optimizar los recursos humanos y técnicos para trascender el acceso a dispositivos digitales y la conectividad en los centros educativos, transformándose de ese modo en una política social y educativa y así lo expresaban:

"Para la integración efectiva de los niños y jóvenes a la Sociedad de la Información y el Conocimiento, es necesario que todos tengan igualdad de oportunidades no solo en el acceso a la información y a las comunicaciones, sino también a nuevos entornos de aprendizaje, acordes al contexto tecnológico de la sociedad actual" (Plan CEIBAL, 2009, p.32).

Para Uriarte y Morales (2014), este movimiento generado a partir de la implementación del Plan Ceibal, al cual Ilamaron "refundacional", involucró a la Universidad de la República, en particular, a través de un grupo de docentes en la reflexión sobre sus prácticas y su relación con las necesidades de la sociedad, de forma crítica y democrática, proponiendo "la integralidad" como una herramienta a través de la cual contribuir a ello.

\section{El Plan Ceibal y la Universidad de la República}

En 2007 un grupo de docentes universitarios comienzan a pensar un marco institucional para involucrarse de forma crítica y reflexiva en los cambios que se estaban produciendo en el país, en particular en el ámbito educativo y en el alcance del Plan Ceibal; surgiendo así el Proyecto Flor de Ceibo (2008-2017) y su continuación el Proyecto Flor de Ceibo Conecta2 (2017 a la actualidad).

En una primera etapa se embarcaron en apoyar la implementación del Plan Ceibal. Este proceso involucró diferentes miradas al interior del Proyecto, pensado desde la integralidad como herramienta de abordaje, desde el diálogo de los tres pilares universitarios la educación, la extensión y la investigación como un todo integrado e involucrando diferentes niveles y actores, donde prevalece el diálogo de saberes; práctica que para el ex rector de extensión universitaria Humberto Tomassino (2017, p.1) significaba abandonar un "modelo de educación bancaria, que lleva a las universidades a ser solo una fábrica de profesionales" y que involucra una función de extensión interactuando en el acto educativo y formando parte de la cotidianeidad de dicho modelo, fomentando el aprendizaje horizontal".

De los primeros objetivos de Flor de Ceibo prevalece el de acompañar la implementación del Plan Ceibal, mientras que forma estudiantes universitarios capaces de abordar de forma crítica y en diálogo constante y crítico con la sociedad. Si bien las acciones concretas fueron modificándose a medida que la realidad nacional y la implementación del Plan se iba adaptando, estos objetivos se mantuvieron en líneas generales (Informe Flor de Ceibo, 2008, 2009, 2010, 2011, 2012, 2013, 2014, 2015 y 2016).

En sus primeras etapas la colaboración entre Plan Ceibal y Flor de Ceibo (2008-2014) significó además de articulaciones de contenidos, estrategias, etc., el apoyo económico del Plan Ceibal mediante convenio para las salidas a territorio, mientras que la Universidad de la República aportaba los cargos y salarios docentes para la implementación del mismo. En los últimos años, el Proyecto Flor de Ceibo se autofinanció hasta que en 2017 hubieron elecciones universitarias y desde el nuevo gobierno se precisaron otras prioridades, que se alejaron de las políticas universitarias que sostenían este tipo de Proyectos en el marco de la Universidad de la República. 
Ante este nuevo panorama, algunos Centros Universitarios, el Centro Universitario Regional sede Paysandú y sede Salto, y el Centro Universitario de Rivera, entendieron pertinente continuar con el Proyecto, a menor escala, permitiendo sostener algunos cargos docentes que junto a una postulación internacional al Programa Beyond the Net de Internet Society, confluyen en la firma de un convenio por el cual el apoyo económico permite solventar las intervenciones estudiantiles en territorio en los departamentos de Paysandú, Rivera y Salto. Surge así el Proyecto Flor de Ceibo Conecta2; que mantiene los principios que sostuvieron el Proyecto Flor de Ceibo, así como sus objetivos. En 2018 el Proyecto se presentó al llamado de apoyo a actividades de extensión universitaria en relación a la ciudadanía digital, consiguiendo el apoyo y financiación de la Comisión de Extensión y Actividades en el Medio para el período julio a diciembre de 2018.

En los últimos años de ejecución del Proyecto Flor de Ceibo y en Flor de Ceibo Conecta2, se sumó a la Universidad de la República, el Consejo de Formación en Educación, institución (terciaria no universitaria) que forma a maestros y profesores para la enseñanza pública de primaria y secundaria en el país, permitiendo la articulación y el enriquecimiento de sus acciones, con cargos docentes y la participación de sus estudiantes.

\section{Flor de Ceibo y Flor de Ceibo Conecta2 en el marco de la 2 da reforma universitaria}

A través de los Proyectos mencionados, se da prioridad a la "integralidad como forma del quehacer univesitario" e "implica reflexividad en relación a las prácticas cotidianas, las relaciones entre estudiantes, docentes, comunidades y otros agentes estatales, tanto en lo que refiere a las metodologías de acción como a los principios teóricos y político-académicos que las orientan" (Uriarte y Morales, 2014 p.6).

Sin embargo, al ir contracorriente a la mayoría de las prácticas académicas de la actualidad universitaria, no ha sido tarea fácil (Uriarte y Morales, 2014), igualmente podemos remontarnos a sus orígenes en la educación pública en ámbitos de investigación, donde se han superado estas prácticas:

"En nuestra historia universitaria se han articulado dos vertientes: la tradición que ubica en un lugar neurálgico a la investigación y producción de conocimiento y la tradición que posiciona la Universidad de cara al país, a sus necesidades y a su gente. Si bien, en ciertas circunstancias, estas vertientes han estado en tensión, la Ley Orgánica las ha conjugado y articulado con la labor de enseñanza [...] históricamente ha habido problemáticas educativas y sociales que han interpelado tanto a maestros como a universitarios, quienes han buscado, en más de una oportunidad respuestas conjuntas" (Bordoli, 2009, p.26).

La integralidad es concebida desde distintas miradas, sin embargo acuerdan en la necesaria articulación de las tres funciones universitarias, la enseñanza, la extensión y la investigación, desde un abordaje por problemas, estrategia asumida desde los Proyectos Flor de Ceibo y Flor de Ceibo Conecta2. En este tipo de abordaje a partir de problemas concretos y contextualizados, la solución cobra sentido tanto para el proceso de formación del estudiante universitario como en la comunidad donde se está interviniendo (Uriarte y Morales, 2014).

Las problemáticas y las posibles soluciones o respuestas se enmarcan en el diálogo entre los diferentes actores involucrados, este diálogo de saberes, académicos y populares, cobra sentido para la construcción de conocimiento nuevo que encuentra a estudiantes y docentes vinculados en dicha 
UTE. Revista de Ciències de l'Educació

2019 núm. 1. Pàg. 48-60
Inclusión digital y democratización del conocimiento. Los Proyectos Flor de Ceibo y Flor de Ceibo Conecta2 en diálogo con las políticas públicas

construcción así como también a integrantes de organizaciones sociales, actores comunitarios, generando nuevos espacios colectivos (Tommasino y Rodríguez, 2011, pp. 24-26).

El origen de esta manera de hacer universidad, la podemos encontrar en una larga tradición, desde los años 70, donde desde la Facultad de Medicina, el entonces decano, "conformó una línea de pensamiento y acción que apuntaba a asociar la enseñanza, la investigación, la extensión y el servicio a la comunidad, en el marco de la atención integral de la salud" (Acosta y Bianchi, 2011, p.125).

Esta idea en concordancia con la idea latinoamericana de Universidad es heredada del movimiento de reforma universitaria que emerge en Córdoba en 1918, que apuntaba a la democratización del conocimiento implicando la lucha contra las desigualdades en tres dimensiones según Arocena (2011):

1. el acceso a la educación superior, tradicionalmente reservado a minorías;

2. la generación de conocimiento de alto nivel, tradicionalmente concentrado en pocos países "centrales" en desmedro de los llamados "países de la periferia" y

3. el uso socialmente valioso del conocimiento, debiéndose al servicio de muchos y no unos pocos como era práctica habitual.

Estos ideales fueron retomados por la Universidad uruguaya, que pretende revitalizarlos en condiciones sociales y culturales propias, en un intento por integrar efectivamente las funciones de enseñanza, investigación y extensión, otorgando a la extensión el rol que ha perdido históricamente en las prácticas universitarias cotidianas, no sin encontrar resistencias (Uriarte y Morales, 2014).

Abordar la integralidad desde la Universidad de la República implicaría trabajar en territorio, interactuando con diferentes actores de la comunidad, movimientos sociales, abordando los problemas en búsqueda de soluciones, poniendo en diálogo y crítica constante entre otras, a las políticas públicas. Permitiendo de este modo un espacio de construcción de ciudadanía. Esto implica que el objetivo último de los programas integrales no es forman profesionales para el mercado laboral, sino colocar a estos al servicio de la sociedad, en espacios de aprendizaje y construcción de conocimientos, democráticos y participativos. No obedece a una lógica donde se es una isla de saber compartible únicamente a su interior, si no en una institución capaz de participar en los procesos de creación y transformación social (Tommasino y Rodríguez, 2011).

\section{Los Proyectos Flor de Ceibo y Flor de Ceibo Conecta2}

Como hemos mencionado en el apartado anterior ambos proyectos conjugan de forma integral las actividades de enseñanza, extensión e investigación, vinculando los distintos niveles de la educación pública y las organizaciones de las comunidades donde arriba, buscando facilitar mediante diferentes estrategias la apropiación social de las tecnologías y el desarrollo de capacidades y competencias digitales; en un intento por contribuir a la vinculación del desarrollo tecnológico, la formación profesional y las problemáticas sociales del país.

Entiende que la formación universitaria se ve enriquecida por la interdisciplina y por tanto la persigue, vinculándola a los usos educativos de las tecnologías digitales, implementando proyectos de intervención e investigación contextualizados.

Según Stolkiner (1999), podemos encontrar dos formas de trabajo abordadas a través del trabajo interdiscplinar: la investigación interdisciplinaria y la formación de equipos asistenciales interdisciplinarios. En el caso de los Proyectos a que hacemos referencia, encontramos una tercera forma 
de trabajo, que es la conformación de un proceso educativo que incorpora la interdisciplinariedad en el equipo docente y en la composición estudiantil.

Desde quienes participamos en este tipo de proyectos, somos conscientes de que ello implica un desafío, en la medida que en:

"Un primer nivel epistemológico y de historia del conocimiento: el simple planteo de la interdisciplina implica un cuestionamiento a los criterios de causalidad, básicamente a los de causalidad lineal, y atenta contra la posibilidad de fragmentación de los fenómenos a abordar. [y en] Un segundo nivel metodológico: tanto en el campo de la investigación, como en el de la asistencia, pensar en un desarrollo interdisciplinario es programar cuidadosamente la forma y las condiciones en que el mismo se desenvuelve. Ya es sabido que la simple yuxtaposición de disciplinas o su encuentro casual no es interdisciplina. La construcción conceptual común del problema que implica un abordaje interdisciplinario, supone un marco de representaciones común entre disciplinas y una cuidadosa delimitación de los distintos niveles de análisis del mismo y su interacción" (Stolkiner, 1999, p.1).

La construcción de conocimiento, sea desde el interior de un campo disciplinario y sus prácticas, o sea desde la interdisciplina, implica necesariamente la puesta en juego de posiciones de poder que en muchos casos deben ser deconstruidas (Stolkiner, 1999).

Bajo esta mirada interdisciplinar, los Proyectos se apoyan en articulaciones y en la generación de dispositivos que acerquen a los diferentes actores y otorguen mayor accesibilidad a poblaciones e instituciones en contextos vulnerados, en los diferentes ámbitos educativos, ya sean formales o informales; es así como a través de los años, se han implementado planes y acciones en escuelas y liceos formales, bibliotecas barriales, centros de atención a la infancia y adolescencia, clubes de niños, asentamientos, cárceles, etc.

Se apoya en una metodología con un abordaje participativo, trabajando en relación a problemas, sostenida en planes con objetivos anuales y de largo plazo. Esta metodología se proyecta en tres fases: a) una fase llamada de diagnóstico, donde junto a la comunidad se realiza el diagnóstico y se identifica el problema a abordar; b) una segunda fase donde se elabora el plan de trabajo conjuntamente entre el docente, los estudiantes y la comunidad y c) una tercera fase donde se realizan las intervenciones, se evalúa por parte de los diferentes actores y se cierran las intervenciones.

En la actualidad funciona bajo un docente coordinador de la Universidad de la República y un equipo docente en territorio conformado por 3 docentes de la Universidad de la República y 3 docentes del Consejo de Formación en Educación asistidos por una articuladora de esta última institución. Los docentes a cargo de grupos son de diferentes disciplinas y servicios; los estudiantes terciarios participantes pertenecen a las distintas instituciones, diferentes carreras y distintos niveles de carrera lo que favorece el intercambio y el enriquecimiento interdisciplinar.

Los ámbitos en que el Proyecto desarrolla sus actividades son definidos por las demandas que arribaron desde centros educativos y organizaciones de la comunidad como por el estudio de factores que intervienen en la inclusión o exclusión digital.

En este sentido, la elección de los territorios en la etapa actual se fundamenta en información aportada por estudios sobre desigualdades territoriales. Veiga (2015) establece que departamentos del norte del país poseen los menores niveles educativos, por debajo de la media nacional. 
Relaciona esta situación con otros indicadores como Necesidades Básicas Insatisfechas y con el índice de Gini para concluir que "los indicadores del nivel de vida representan aspectos estratégicos del desarrollo humano a nivel local, y guardan estrecha relación con las otras dimensiones e indicadores elaborados", a su vez "demuestran tendencias coincidentes respecto a los menores niveles socioeconómicos prevalecientes en los departamentos del norte del país, como resultado de sus características y menor desarrollo a nivel general" (Veiga, 2015, p.63).

Las características de los territorios seleccionados justifican trabajar por la democratización del conocimiento, buscando potenciar la apropiación y el uso de Internet para la mejora de la calidad de vida y el desarrollo de capacidades para ejercer una ciudadanía participativa.

Es así que Flor de Ceibo Conecta2 mediante sus prácticas busca potenciar la apropiación, desarrollando capacidades y competencias (Larraz 2013, Lázaro-Cantabrana, Estebanell y Tedesco 2015) relacionadas con estrategias de uso y usos estratégicos de las herramientas tecnológicas -Internet incluida-, planteadas por Kemly Camacho (2001) y de uso significativo de Martínez y Gómez (2011) como posibilidades de uso desde el punto de vista de la apropiación social de la tecnología, poniendo énfasis en los procesos de enseñanza-aprendizaje.

En suma desde Flor de Ceibo Conecta2, al igual que en la experiencia de su antecesor Flor de Ceibo, se apunta a construir una mirada intedisciplinaria e integral para abordar el campo de problemas, se concibe el desarrollo científico-tecnológico como un bien público, que debería contribuir a una autonomía creciente en los actores involucrados en los procesos de incorporación de las tecnologías digitales; abordando sus estrategias desde la integralidad, mediante una metodología embarcada en la resolución de problemas concretos y relevantes con la participación conjunta de todos los actores involucrados, desde la identificación y construcción del problema hasta la búsqueda y concreción de soluciones posibles.

\section{Reflexiones finales}

De los intercambios docentes y estudiantiles, junto a las comunidades, provistos de reflexión teórica, investigación e intervención en las diferentes instancias de participación en los Proyectos Flor de Ceibo y Flor de Ceibo Conecta2, se concibe a las tecnologías digitales como herramientas para la inclusión digital y social, aunque por si solas no es suficiente, ya que se necesitan de procesos que tiendas a la apropiación social de la tecnología y al desarrollo de capacidades y competencias en lo educativo (Flor de Ceibo, 2016; Morales y Onetto, 2018).

Asimismo, se entiende que la metodología utilizada en estos procesos, abordaje por problemas, es pertinente ya que el uso de las tecnologías debe adquirir sentido y significado para quienes las utilizan, y esto se corrobora en contextos particulares; que el abordaje integral atiende la complejidad del problema identificado junto a la comunidad, en múltiples dimensiones y que la interdisciplinariedad es relevante para comprender y abordar los procesos de enseñanza - aprendizaje (Flor de Ceibo, 2016, Morales y Onetto, 2018).

Que al pensar que la apropiación tecnológica o social de la tecnología lleva implícito un vínculo funcional ya que el sujeto interioriza o la incorpora como herramientas a su disposición con un sentido propio, se trascienden los usos básicos (Morales y Onetto, 2018). 


\section{Bibliografía}

Acosta, B., \& Bianchi, D. (2011) "Programas Integrales. Instrumentos para la transformación universitaria". En Universidad en movimiento. Debates y memorias del $X$ Congreso Iberoamericano de Extensión Universitaria. (Montevideo)

AGESIC (2016) Agenda Uruguay digital. Transformación con equidad. 2020. Presidencia de la República. Disponible en: https://www.agesic.gub.uy/innovaportal/file/6122/1/agenda-uruguay-digital---enerofinal.pdf

Almirón, R., \& Folgar. 2009 "La escuela cambia de piel" En: Gunther Cyranek (comp.) En el camino del Plan CEIBAL. Referencias para padres y Educadores. (Montevideo - UNESCO)

Arocena, R. (2011) "Curricularización de la extensión: ¿por qué, cuál, cómo?" En Comisión Sectorial de Extensión y Actividades en el Medio (comp.) Integralidad: tensiones y perspectivas. Cuadernos de Extensión 1. (Montevideo).

Bordoli, E. (2009) "La extensión universitaria como una experiencia de "comunidad" educativa" En: Pensar la escuela como proyecto [político] pedagógico. (Montevideo: Psicolibros - Waslala)

Bordoli, E., \& Romano, A. (2009) "Introducción" En: Pensar la escuela como proyecto [político] pedagógico. (Montevideo: Psicolibros - Waslala).

Cabello, R. (2014). Reflexiones sobre inclusión digital como modalidad de inclusión social. VIII Jornadas de Sociología de la UNLP, 3 al 5 de diciembre de 2014, Ensenada, Argentina. En Memoria Académica. Disponible en: http://www.memoria.fahce.unlp.edu.ar/trab_eventos/ev.4796/ev.4796.pdf

Camacho, K. (2001): Internet: ¿una herramienta para el cambio social? México: FLACSO.

Castells, M. (1997) La era de la información. Alianza Madrid.

D'Ambrosio, L. (2009) "Cuando el esqueleto humano reemplaza al bronce. Repensando las imágenes y los abordajes de la identidad nacional en la Escuela" En: Pensar la escuela como proyecto [político] pedagógico. (Montevideo: Psicolibros - Waslala).

Da Silva, M., \& López. L. (2014). Pensando el Plan Ceibal desde la perspectiva de la Acción Pública y la Teoría del Actor-Red. Athenea Digital: revista de pensamiento e investigación social, 14(1), 49-68. DOI:10.5565/rev/athenead/v14n1.939

Da Silva, M. \& Morales, MJ (2010) Plan de Conectividad Educativa Básica en Línea: Política pública y procesos de identidad en Uruguay. En Diálogos transdisciplinarios en la Sociedad de la Información. Fundación REDES. La Paz, Bolivia.

García-Urea, S. (2007). La Democratización Tecnológica y la Inclusión Social: Un Análisis desde lo Sociocultural. Disponible en: http://www.analitica.com/premium/ediciones2007/4876591.asp

Grandi. R. (2009) "Prólogo" En: Gunther Cyranek (comp.) En el camino del Plan CEIBAL. Referencias para padres y Educadores. (Montevideo - UNESCO) 
UTE. Revista de Ciències de l'Educació

2019 núm. 1. Pàg. 48-60
Inclusión digital y democratización del conocimiento. Los Proyectos Flor de Ceibo y Flor de Ceibo Conecta2 en diálogo con las políticas públicas

Informes Flor de Ceibo, 2008, 2009, 2010, 2011, 2012, 2013, 2014, 2015 y 2016 disponibles en: www.flordeceibo.edu.uy

Lago-Martínez, S., Amado, S., Alvarez, A., Andonegui, F., \& Soto, C. (2016). Supuestos y particularidades de las políticas de inclusión digital en el Cono Sur y en Argentina. In IX Jornadas de Sociología de la UNLP 5 al 7 de diciembre de 2016 Ensenada, Argentina. Universidad Nacional de La Plata. Facultad de Humanidades y Ciencias de la Educación. Departamento de Sociología. Disponible en: http://jornadassociologia.fahce.unlp.edu.ar/ix-jornadas/actas-2016/PONmesa47LagoMartinez.pdf

Lago-Martínez, S., Amado, S., \& Vidaurre, M (2015): Inclusión digital educativa y comunicación: cartografía de las políticas públicas en la región latinoamericana, en Actas del VIII SeminarioRegional (Cono Sur) ALAIC. ECI - ALAIC. http://www.eci.unc.edu.ar/archivos/congresos/ALAIC/eje11/alaic-1168.pdf

Larraz, V. (2013) La competència digital a la Universitat. Tesis doctoral. Universidad de Andorra.

Lázaro, J.L. (2015) La competència digital Docent com a eina per garantir la qualitat en l'ús de les TIC en un centre escolar. Tesis doctoral. Universitat Rovira i Virgili. Tarragona.

Lázaro Cantabrana, J. L., Estebanell Minguell, M., \& Tedesco, J. C. (2015). Inclusión y cohesión social en una sociedad digital. RUSC. Universities and Knowledge Society Journal, 12(2). págs. 44-59. doi http://dx.doi.org/10.7238/rusc.v12i2.2459

Martínez J., \& Gómez R. (2001) Más allá del acceso a internet ¿Qué puede hacer internet por una mayor equidad Social? Disponible en: https://idl-bncidrc.dspacedirect.org/bitstream/handle/10625/29736/119878_s.pdf?sequence=1\&isAllowed=y Consultado en abril 2019. Fundación Acceso. Serie "Pensando las políticas públicas" N5.

Moraes, E. (2009) "Prólogo" En: Gunther Cyranek (comp.) En el camino del Plan CEIBAL. Referencias para padres y Educadores. (Montevideo - UNESCO)

Morales, M. J. (2017). Apropiación social de la tecnología por parte de la población de la localidad de Cebollatí en Uruguay. En A. Rivoir (ed.) Análisis empíricos y reflexiones teóricas (151- 162). Montevideo: Ediciones Universitarias - UCUR.

Morales, M.J., \& Onetto, A. (2018) Proyecto Flor de Ceibo Conecta2. Una experiencia para la inclusión digital de niños/as y adolescentes. En X. Carrera et al (eds.), EDUcación con TECnología. Un compromiso social. Aproximaciones desde la investigación e innovación (pp. 1487- 1992) Lleida: Edicions de la Universitat de Lleida. ISBN: 978-84-9144-126-7 DOI 10.21001/edutec.2018 Disponible en: https://repositori.udl.cat/handle/10459.1/64975

Rivoir, A. (2013b) Plan Ceibal e inclusión social. Perspectivas interdisciplinarias. Editorial: UDELAR/Plan Ceibal, Montevideo. ISSN/ISBN: 9789974838307

Rivoir, A., \& Lamschtein, S. (2012). Cinco años del Plan Ceibal. Algo más que una computadora. Montevideo: UNICEF

Stolkiner, A. (1999) La Interdisciplina: entre la epistemología y las prácticas. En EL CAMPO Psi, Abril 1999, Buenos Aires, Argentina http://www.campopsi.com.ar/lecturas/stolkiner.htm 
Tommasino, H., \& Rodríguez, N. (2011) "Tres tesis básicas sobre extensión y prácticas integrales en la Universidad de la República" En Comisión Sectorial de Extensión y Actividades en el Medio (comp.) Integralidad: tensiones y perspectivas. Cuadernos de Extensión 1. (Montevideo).

Tomassino, H. (2017) Entrevista realizada por la Secretaría de extensión de la Universidad Nacional del Centro de la Provincia de Buenos Aires. 5 de Julio de 2017. Recuperada en: http://extension.unicen.edu.ar/tommasino-la-universidad-no-debe-ser-solo-una-fabrica-deprofesionales/

UNESCO (2005). Hacia las sociedades del conocimiento. Disponible en: http://portal.UNESCO.org/culture/es/ev.php-

URL_ID=29619\&URL_DO=DO_TOPIC\&URL_SECTION=201.html

UNESCO (2009). Directrices sobre políticas de inclusión en la educación. Disponible en: http://unesdoc.UNESCO.org/images/0017/001778/177849s.pdf

Uriarte, P., \& Morales, M. J. (2014) ¿Qué queremos decir con Integralidad? Una mirada a través del Proyecto Flor de Ceibo de la Universidad de la República. En: Revista Encuentros Uruguayos Volumen VII, Número 1, Octubre 2014, pp. 54-78.

Veiga, D. (2015) Estructura socio-económica y desarrollo local en Uruguay. Ponencia presentada en las $X$ Jornadas de investigación de la Facultad de Ciencias Sociales. UDELAR 